\title{
Meta-Analysis: Superior Treatment Response in Asian Patients with Hepatitis C Virus Genotype 6 versus Genotype 1 with Pegylated Interferon and Ribavirin
}

\author{
Nghia H. Nguyen ${ }^{a}$ Shelley A. McCormack ${ }^{a}$ Philip Vutien $^{b}$ Brittany E. Yee ${ }^{a}$ \\ Pardha Devaki $^{c}$ David Jencks ${ }^{d}$ Mindie H. Nguyen ${ }^{e}$ \\ ${ }^{a}$ School of Medicine at the University of California, San Diego, Calif., bepartment of Medicine, Rush University \\ Medical Center, Chicago, III., ' Department of Medicine, Detroit Medical Center/Wayne State University, \\ Detroit, Mich., and d Department of Medicine, Stanford University, and ${ }^{\mathrm{e}}$ Division of Gastroenterology and \\ Hepatology, Stanford University Medical Center, Palo Alto, Calif., USA
}

\section{Key Words}

Hepatitis C virus · Sustained virologic response · Genotype $6 \cdot$ Genotype 1

\begin{abstract}
Objective: Our goal was to systematically and quantitatively assess treatment response between Asian patients with hepatitis $C$ virus genotype 6 (HCV-6) and hepatitis $C$ virus genotype $1(\mathrm{HCV}-1)$ treated for 48 weeks with pegylated interferon and ribavirin. Methods: We performed a literature search in MEDLINE and EMBASE for 'genotype 6' in August 2013. Additional abstracts from major international scientific conferences from 2012 to 2013 were reviewed. Studies included were original articles with $\geq 10$ treatment-naïve Asian HCV-6 patients. Exclusion criteria were coinfections with hepatitis B virus, HIV and/or other liver diseases. Heterogeneity was defined as a Cochrane $Q$ test with a $p$ value of 0.10 and an $\mathrm{I}^{2}$ statistic of $>50 \%$. Results of a random-effects model are reported. Results: A total of 1,046 (503 HCV-6; 543 $\mathrm{HCV}$-1) patients from 12 studies were included in the analysis. The pooled sustained virologic response (SVR) rate was
\end{abstract}

80.2\% (95\% Cl 74.3-85.0, Q statistic $=20.87, \mathrm{p}<0.035 ; \mathrm{I}^{2}=$ 47.3\%) for HCV-6 and $62.5 \%(95 \% \mathrm{Cl} 41.9-79.4$, Q statistic = 52.41, $\mathrm{p}<0.001 ; \mathrm{I}^{2}=92.37$ ) for HCV-1 patients. HCV-6 patients had a significantly higher SVR rate compared to HCV-1 patients (odds ratio $2.73,95 \% \mathrm{Cl} 1.69-4.41, \mathrm{p}<0.001$ ). Approximately one fourth of patients without early virologic response (EVR) achieved SVR, regardless of genotype (HCV$1, n=6 / 23 ; \mathrm{HCV}-6, \mathrm{n}=4 / 21)$. Conclusions: Asian patients with HCV-6 can expect higher SVR rates ( 80\%) than HCV-1 patients ( 63\%). EVR as a stopping rule is less clear in Asian patients with HCV-6 and HCV-1.

๑) 2015 S. Karger AG, Basel

\section{Introduction}

Chronic infection with hepatitis $\mathrm{C}$ virus (HCV) is a major global health problem affecting approximately 170 million people [1]. Chronic infection causes significant sequelae and frequently leads to end-stage liver disease and hepatocellular carcinoma [2]. In Southeast Asia, $\mathrm{HCV}$ prevalence in some countries $(6-7 \%$ in Vietnam

\section{KARGER 125}

(c) 2015 S. Karger AG, Base

0300-5526/15/0581-0027\$39.50/0

E-Mail karger@karger.com

www.karger.com/int
Assoc. Prof. Mindie H. Nguyen, MD, MAS

Division of Gastroenterology and Hepatology

Stanford University Medical Center

750 Welch Road, Suite 210, Palo Alto, CA 94304 (USA)

E-Mail mindiehn@stanford.edu 
and Thailand) is higher than the US prevalence of $1.8 \%$ [1]. HCV genotype 1 (HCV-1) and the lesser known genotype 6 (HCV-6) are also the 2 most common genotypes in parts of Southeast Asia, Hong Kong and Southern China [1].

$\mathrm{HCV}$ genotype is a major independent predictor of sustained virologic response (SVR, defined as undetectable HCV RNA at 24 weeks after the end of therapy) in patients treated with pegylated interferon and ribavirin (PEG-IFN + RBV) [1]. While there are 6 known HCV genotypes worldwide, HCV genotypes 1-3 are predominant in Western countries, and large registration trials with PEG-IFN + RBV have been conducted and focused on these 3 genotypes. HCV-1 (40-50\%) has lower SVR rates than the more treatment-favorable genotypes 2 and $3(70-80 \%)$ [2]. However, results from these studies often stem from non-Asian patients and may not be generalizable to Asian patients.

Although there have been several studies published on Asian patients with $\mathrm{HCV}-1$, there is limited treatment information on Asian patients with HCV-6 and even less data directly comparing SVR rates in patients with these 2 genotypes [3-12]. Some studies suggest that the SVR rate in HCV-6 patients is superior to that in HCV-1 patients, but these studies are largely limited by their small sample sizes [4, 10-21].

Most recently, triple therapy with PEG-IFN + RBV and sofosbuvir has been approved by the Food and Drug Administration in the US for the treatment of HCV-1 [22]. However, given the high retail cost of sofosbuvir (Sovaldi ${ }^{\circledR}$, Gilead Sciences, Foster City, Calif., USA; USD 84,000 for 12 weeks of treatment in the USA), this therapy may be cost prohibitive $[22,23]$. While Gilead Sciences has proposed price reductions for low- to middle-income countries (USD 5,000 in Thailand, USD 2,000 in India), comments from directors of the Médecins sans Frontières Access Campaign [24] suggest that 'at these prices, access in middle-income countries - where $75 \%$ of the world's poor actually live - is likely to be extremely limited', given the income disparity in such areas. Data on new direct-acting antiviral therapy for HCV-6 is also very limited with only 6 patients with HCV-6 included in the landmark NEUTRINO study with sofosbuvir-based therapy [25]. Therefore, PEG-IFN + RBV will likely remain the main therapeutic option for Asian patients residing in these regions for the near future.

Our goal was to quantitatively and qualitatively compare treatment responses to PEG-IFN + RBV between Asian patients infected with $\mathrm{HCV}-6$ versus $\mathrm{HCV}-1$.

\section{Materials and Methods}

Data Sources and Searches

We performed a comprehensive literature search in PubMed in October 2013 with the search term 'genotype 6'. The search was limited to MEDLINE-indexed articles only and included studies in non-English languages. We also performed a manual search for the term 'genotype 6' in abstracts from annual international scientific meetings between 2012 and 2013 of the American Association for the Study of Liver Diseases (AASLD), Digestive Disease Week (DDW), Asian Pacific Study of the Liver (APASL) and European Association for the Study of the Liver (EASL). An EMBASE search was also conducted for the same period using the search term 'genotype 6/exp'.

\section{Study Selection}

Original studies with $\geq 10 \mathrm{HCV}-6$ treatment-naïve Asian patients treated with PEG-IFN + RBV were included. Studies were excluded if study cohorts included patients with coinfection with hepatitis B, hepatitis D or HIV. In studies that included both HCV6 and $\mathrm{HCV}-1$ patients, we included these $\mathrm{HCV}-1$ patients as the HCV-1 comparison group for our study. Articles were reviewed independently by two of the authors (N.H.N. and S.A.M.) and checked by a third author (M.H.N.), discrepancies being resolved by consensus.

\section{Data Extraction}

For each study, we collected information on study characteristics (country of origin, practice setting, collaboration), study design, study type [randomized controlled trial (RCT) vs. observational], intention-to-treat (ITT) analysis and baseline patient characteristics (ethnicity, age, gender, alanine transferase, fibrosis and HCV RNA levels). We also collected baseline treatment information and treatment response data, namely rapid virologic response (RVR, defined as undetectable HCV RNA after 4 weeks of treatment), early virologic response (EVR, defined as $<50 \mathrm{IU} / \mathrm{ml}$ or $>2$ log drop from baseline HCV RNA after 12 weeks of treatment) and SVR.

\section{Statistical Analysis}

Pooled event rates and odds ratios (ORs) with corresponding 95\% CIs were gathered using random-effects models and the inverse variance method [26]. Study heterogeneity was assessed through a $\chi^{2}$-based Cochrane Q statistic, with $\mathrm{p} \leq 0.10$ and $\mathrm{I}^{2} \geq 50 \%$ considered substantial heterogeneity [26]. Influence analysis to ensure the robustness of the pooled estimate was conducted for the primary outcome. In studies with zero cell counts, a fixed value of 0.5 was added to all cells of the study result tables [26]. All statistical tests were 2 -sided. All calculations were performed using Comprehensive Meta-Analysis, version 2 (Biostat, Englewood, N.J., USA).

\section{Results}

\section{Study Search Results}

In total, we identified 161 and 251 articles through PubMed and EMBASE, respectively, and 14,648 abstracts 
Fig. 1. Flowchart of studies included.

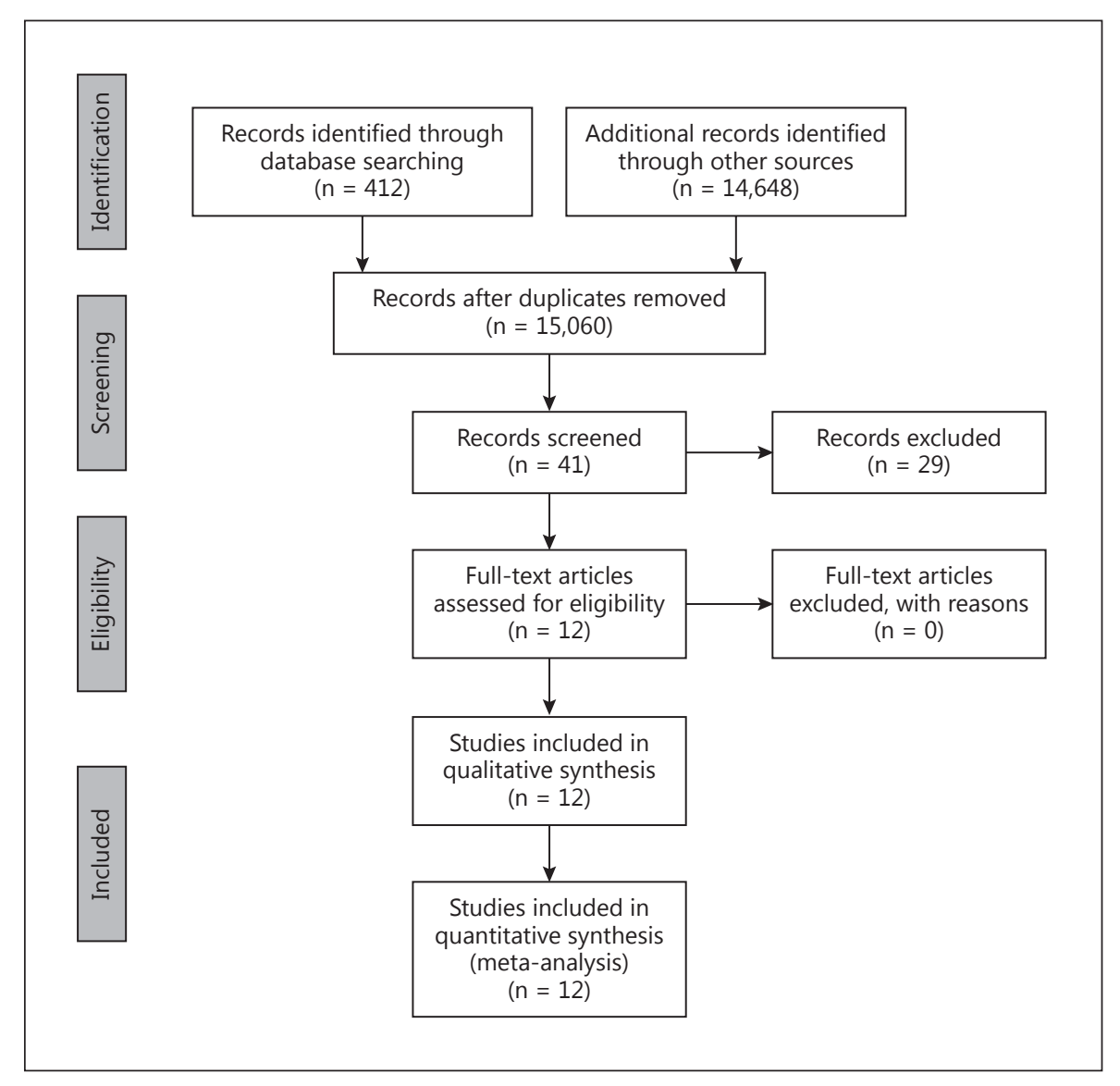

from AASLD, DDW, APASL and EASL. Forty-one studies were identified and assessed for more detailed evaluation and inclusion for analysis $[4,10-12,14-21,27-53]$. Ten studies did not contain original or extractable data for analysis [13, 45-53]. Eight studies were identified as redundant and thus excluded; these were duplicates found during our search or earlier abstracts of full articles that were later published $[15,19,28-31,40,41]$. Six studies included less than $10 \mathrm{HCV}-6$ patients [32-34, 42-44]. Four studies did not include patients treated with PEGIFN + RBV [35-38]. One study included patients with coinfections [41]. Ultimately, 12 studies (8 full articles and 4 abstracts) $[4,10-12,14-21]$ met our inclusion criteria and were included in this meta-analysis (fig. 1). All 12 studies included HCV-6 patients treated for 48 weeks. The characteristics of the 12 studies are described in table 1.

\section{Study and Patient Characteristics}

In the primary analysis, a total of 1,046 (503 HCV-6; 543 HCV-1) patients from 12 studies were included (ta- ble 1). Six studies were prospective, 4 were retrospective and 2 were of unknown design $[4,10-12,14-21]$. Of the 12 studies, 2 were RCTs $[20,21]$, while the remaining studies were observational or nonrandomized trials [4, $10-12,14-19]$. Study origins included 3 from the USA $[14,15,21], 3$ from Southeast Asia (1 from Thailand and 2 from Vietnam) $[11,16,20]$ and 6 from China $[4,10,12$, 16-18]. The majority of studies were performed in a university or tertiary referral setting. All studies evaluated SVR overall and in Asian patients with HCV-6 [4, 10-12, 14-21]. Five studies directly compared Asian patients with HCV-6 versus HCV-1 [4, 10-12, 15]. All subjects were Asian and most of them were male. Only patients treated with PEG-IFN + RBV for 48 weeks were included in the analysis.

\section{SVR in HCV-6 and HCV-1 Patients Treated for 48 Weeks}

The pooled event rate of SVR in $503 \mathrm{HCV}-6$ patients was $80.2 \%$ (95\% CI 74.3-85.0, Q statistic $=20.87, \mathrm{p}<$ $\left.0.035 ; \mathrm{I}^{2}=47.3 \%\right)[4,10-12,14-21]$. In a funnel plot anal- 
Table 1. Characteristics of studies included in the treatment analysis of Asian patients with HCV -6 and HCV-1

\begin{tabular}{|c|c|c|c|c|c|c|c|}
\hline \multirow[t]{2}{*}{ Study } & \multirow[t]{2}{*}{ Population } & \multicolumn{3}{|l|}{ HCV-6 } & \multicolumn{3}{|l|}{$\mathrm{HCV}-1$} \\
\hline & & males, $\mathrm{n}$ & age, years & $\mathrm{n}$ & males, $\mathrm{n}$ & age, years & $\mathrm{n}$ \\
\hline Thu Thuy et al. [20], 2012 & Vietnam & $65(62)$ & $48.6 \pm 8.4$ & 70 & n.a. & n.a. & n.a. \\
\hline Lam et al. [21], 2010 & USA & $28(47)$ & $52.8 \pm 8.0$ & 33 & n.a. & n.a. & n.a. \\
\hline Tsang et al. [12], 2010 & Hong Kong & $47(67)$ & 50 & 70 & $44(63)$ & 48 & 70 \\
\hline Nguyen et al. [14], 2008 & USA & $45(68)$ & $50 \pm 10$ & $12^{\mathrm{a}}$ & n.a. & n.a. & n.a. \\
\hline Seto et al. [18], 2013 & Hong Kong & $41(68)$ & 49 & 60 & n.a. & n.a. & n.a. \\
\hline Shao et al. [19], 2012 & China & unknown & unknown & 28 & n.a. & n.a. & n.a. \\
\hline Cai et al. [17], 2011 & China & unknown & unknown & 84 & n.a. & n.a. & n.a. \\
\hline Pham et al. [16], 2009 & Vietnam & unknown & unknown & 42 & n.a. & n.a. & n.a. \\
\hline
\end{tabular}

Results are reported as means $\pm \mathrm{SD}$, numbers with percentages given in parentheses or medians of study populations with ranges given in parentheses and do not necessarily reflect only patients with HCV-6 and HCV-1. n.a. = No data available.

a Thirty-one patients were treated with standard IFN therapy and were not included in the analysis.

ysis for publication bias, the study by Rao et al. [10] had the largest standard error, namely 1.5 (data not shown). This observation could be explained by the small sample of HCV- 6 patients $(n=14)$ who achieved a $100 \%$ SVR success rate in their study. In an influence analysis using the 1 -study removal method, there was only a small change $(\sim 1 \%)$ in the pooled event rate when their study was omitted, demonstrating the robustness of our estimate.

In the 9 studies with ITT analysis, the pooled event rate was $80.4 \%$ (95\% CI 73.2-86.1), which was similar to the SVR rate observed in the 3 studies with non-ITT analysis (80.2\%, 95\% CI 66.3-89.2). Significant heterogeneity was not indicated in the subgroup study with ITT analysis ( $\mathrm{Q}$ statistic $\left.=13.03, \mathrm{p}=0.11 ; \mathrm{I}^{2}=38.624\right)$. The SVR rate was lower in RCTs, $74.6 \%$ (95\% CI 58.7-85.8), than in observational and nonrandomized studies, $81.6 \%$ (95\% CI 75.2-86.7). We observed significant heterogeneity in the subgroup analysis with non-RCTs ( $Q$ statistic $=18.08$, $\mathrm{p}=0.034 ; \mathrm{I}^{2}=50.208$ ).

In the 5 studies with a total of 543 Asian HCV-1 patients, the pooled SVR rate was $62.5 \%$ (95\% CI 41.9-79.4, $\mathrm{Q}$ statistic $\left.=52.41, \mathrm{p}<0.001 ; \mathrm{I}^{2}=92.37\right)$. All studies were observational in nature and analyzed SVR rates according to the ITT $[4,10-12,15]$.

\section{Direct Comparison between SVR Rates in Asian \\ Patients with $\mathrm{HCV}-6$ and $\mathrm{HCV}-1$}

In the 5 studies with a direct comparison between Asian patients with HCV-6 and HCV-1, there were a to- tal of $174 \mathrm{HCV}-6$ and $543 \mathrm{HCV}-1$ patients. The pooled SVR rates were $77.1 \%(95 \%$ CI $70.0-82.9)$ and $62.5 \%$ (95\% CI 41.9-79.4), respectively. There was a statistically significant difference between SVR rates in HCV-6 versus $\mathrm{HCV}-1$ patients (OR 2.73, 95\% CI 1.69-4.41, $\mathrm{p}<$ 0.001 ; fig. 2). These studies were all observational or nonrandomized in nature and analyzed SVR rates according to the ITT $[4,10-12,15]$. No significant heterogeneity was indicated $\left(\mathrm{Q}\right.$ statistic $=1.56, \mathrm{p}=0.82 ; \mathrm{I}^{2}=$ $0 \%$ ). Since $\mathrm{I}^{2}$ was $0 \%$, effect sizes and corresponding CIs were the same between both random- and fixed-effects models.

\section{Rates of SVR in HCV-6 and HCV-1 Patients with EVR}

In the 4 studies with EVR and SVR data of HCV-6 patients, there were a total of 207 HCV -6 patients $[11,12$, $20,21]$. The pooled SVR rate overall in these studies was 74.8\% (95\% CI 68.4-80.2), while the pooled EVR rate was 88\% (95\% CI 82.6-91.9). In cases with EVR, 81.5\% (95\% CI 75.2-86.5) achieved SVR. Of the 21 patients who did not have an EVR, 23.8\% (95\% CI 7.0-56.5) subsequently achieved SVR. In the 3 studies with a direct comparison between HCV -6 patients with and without EVR, patients with EVR were significantly more likely to have SVR compared to those without EVR (OR 13.7, 95\% CI 3.83$49.2, \mathrm{p}<0.001)$.

In the 2 studies that contained EVR data of HCV-1 patients, there were a total of $91 \mathrm{HCV}-1$ patients $[4,12]$.
30
Intervirology 2015;58:27-34 DOI: $10.1159 / 000369097$
Nguyen/McCormack/Vutien/Yee/ Devaki/Jencks/Nguyen 


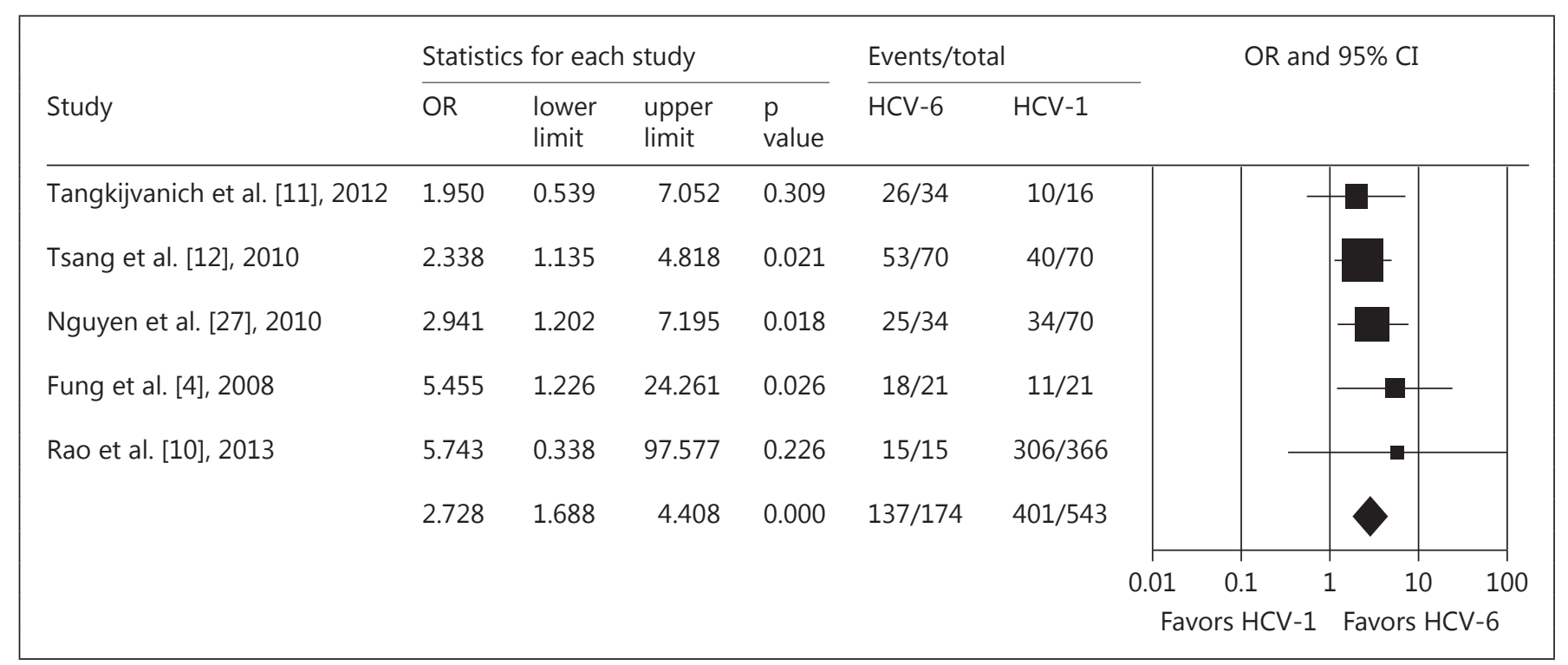

Fig. 2. Comparison between patients with HCV-6 and HCV-1.

The pooled SVR rate in these studies was $56.0 \%$ (95\% CI 45.7-65.9), while the pooled EVR rate was $74.7 \%$ (95\% CI 64.8-82.6). In cases with EVR, 66.1\% (95\% CI 54.2-76.4) achieved an SVR $[4,12]$. Of the 23 patients without EVR, 26.2\% (95\% CI 12.3-47.5) subsequently achieved SVR. Patients with EVR had a significantly higher OR of achieving SVR compared to patients without EVR (OR 5.59, 95\% CI 1.93-16.2, $\mathrm{p}=0.002$ ).

\section{Discussion}

In the current meta-analysis, we included a total of 12 studies with $503 \mathrm{HCV}-6$ and $543 \mathrm{HCV}-1$ patients. The pooled SVR rate was $80.2 \%$ (95\% CI 74.3-85.0) in HCV6 patients and $62.5 \%$ (95\% CI 41.9-79.4) in HCV-1 patients. HCV-6 patients were significantly more likely to achieve SVR compared to HCV-1 patients (OR 2.73, 95\% CI 1.69-4.41, $\mathrm{p}<0.001)$. Our result represents the first large and comprehensive study to date to evaluate SVR rates between these patients.

In cases with $\mathrm{HCV}-1$, our pooled SVR rate $(\sim 60 \%)$ is higher than findings in non-Asian HCV-1 patients from large registration trials $(\sim 40-50 \%)$ and comparable to studies that specifically evaluated treatment data in Asian HCV-1 patients [3, 5-9]. The high SVR rates in our Asian patients with HCV-1 could be explained by the CC genotype (a polymorphism near interleukin-28 on chromo-

HCV-6 Patients Have Superior SVR Rates to HCV-1 Patients some 19 that influences SVR rates with IFN-based therapies) known to be more common in areas where most of these Asian patients with $\mathrm{HCV}-6$ and $\mathrm{HCV}-1$ reside [17, $18,54,55]$.

In our study, HCV-1 and HCV-6 patients with EVR were more likely to achieve SVR compared to those without EVR, which is consistent with the established literature on the positive predictive value of EVR [56]. However, approximately one fourth of patients without EVR also achieved SVR subsequently, regardless of genotypes. While previous studies have recommended that the absence of EVR is a good stopping rule in patients with $\mathrm{HCV}-1$, data from this recommendation was derived from studies with largely non-Asian patients and/or small numbers of patients without EVR [2, 9, 56]. Two large RCTs with treatment-naïve Asian patients with HCV-1 by Liu et al. [9] $(n=308)$ and Yu et al. [57] $(n=200)$ also found that $0 \%$ of patients without EVR achieved SVR and also suggested that treatment could be stopped in those without EVR; their recommendations were based on data of a very small number of patients without EVR ( $n=4$ and $n=7$, respectively). On the other hand, based on our meta-analysis data of the $23 \mathrm{HCV}-1$ patients without EVR, we cannot recommend stopping treatment in such patients without EVR, since a quarter of these patients eventually achieved SVR.

Additionally, the economic burden of not achieving SVR and/or retreatment is much higher in patients that do 
not achieve SVR versus those that achieve SVR [58]. In this study by Backx et al. [58], the authors demonstrated that failure to achieve SVR was associated with a 13-fold increase in health care-related costs, which was related to a higher likelihood of a patient transitioning to a severer disease state that required more health care, while the costs were 56-fold higher for retreated patients. Given that PEG-IFN + RBV is associated with significant side effects and requires a full year of treatment, the risk, benefits and cost savings of treatment should be discussed with the patient, and the decision to continue treatment if a patient does not achieve EVR should be individualized.

While our data did not allow us to examine responseguided therapy for shortened treatment duration, data from 2 RCTs by Liu et al. [9] and Yu et al. [57] suggest that HCV-1 patients with RVR may be treated for 24 weeks with PEG-IFN + RBV. In contrast, for patients who continue to experience detectable HCV RNA after 24 weeks with PEG-IFN + RBV, studies have suggested that these patients may also stop treatment [2]. In Asian patients with HCV-6, an ongoing RCT with PEG-IFN + $\mathrm{RBV}$ in patients with RVR has produced results that suggest there are no significant differences between 24 and 48 weeks of treatment [59]. Until published data becomes available from this trial, patients with HCV-6 should be treated for 48 weeks with PEG-IFN + RBV.

One of the limitations of our meta-analysis was the small number of studies available, which affected our ability to detect significant publication bias and perform additional subgroup analyses. To account for the limited data available, we sought to be as inclusive as possible and included studies of relatively different characteristics. We also reported results from random-effects models in an at- tempt to provide a more conservative estimate. Another limitation is the potential selection bias of patients, as most of our data were derived from observational studies. However, our findings are more likely to be generalizable to patients in routine clinical settings, since observational studies have broader inclusion criteria for study patients and are more likely representative of the population at large.

In summary, Asian patients with HCV-6 can expect a higher SVR rate ( $\sim 80 \%)$ than Asian patients with HCV -1 when treated for 48 weeks with PEG-IFN + RBV ( 63\%). Lack of EVR may not be a good stopping rule for Asian patients with HCV-6 or HCV-1. Compared to the high cost of newer therapies, PEG-IFN + RBV may remain an acceptable option for Asian patients residing in resourcelimited regions with HCV-6 and perhaps also for Asian patients with $\mathrm{HCV}-1$, especially given the higher SVR rates with both genotypes with PEG-IFN + RBV in this ethnic group.

\section{Acknowledgment}

This study was funded in part by the NIH National Center for Research Resources, TL1 training grants and 1TL1RR03197, to Nghia H. Nguyen and Shelley A. McCormack.

\section{Disclosure Statement}

Nghia H. Nguyen, Shelley A. McCormack, Philip Vutien, Brittany E. Yee, Pardha Devaki and David Jencks have no conflicts of interest to declare.

Mindie H. Nguyen has served as a consultant and an advisory board member for Gilead Sciences Inc., Bristol-Myers Squibb, Novartis and Bayer.

\section{References}

1 Wantuck JM, Ahmed A, Nguyen MH: Review article: the epidemiology and therapy of chronic hepatitis $\mathrm{C}$ genotypes 4, 5 and 6 . Aliment Pharmacol Ther 2014;39:137-147.

2 Ghany MG, Strader DB, Thomas DL, Seeff LB; American Association for the Study of Liver Diseases: Diagnosis, management, and treatment of hepatitis C: an update. Hepatology 2009;49:1335-1374.

3 Chuang WL, Yu ML, Dai CY, Chang WY: Treatment of chronic hepatitis $\mathrm{C}$ in southern Taiwan. Intervirology 2006;49:99-106.

4 Fung J, Lai CL, Hung I, et al: Chronic hepatitis $C$ virus genotype 6 infection: response to pegylated interferon and ribavirin. J Infect Dis $2008 ; 198: 808-812$.

\footnotetext{
5 Hepburn MJ, Hepburn LM, Cantu NS, Lapeer MG, Lawitz EJ: Differences in treatment outcome for hepatitis $\mathrm{C}$ among ethnic groups. Am J Med 2004;117:163-168.

6 Kuboki M, Iino S, Okuno T, et al: Peginterferon alpha-2a $(40 \mathrm{kD})$ plus ribavirin for the treatment of chronic hepatitis $C$ in Japanese patients. J Gastroenterol Hepatol 2007;22:645-652.

-7 Lee H, Choi MS, Paik SW, et al: Peginterferon alfa-2a plus ribavirin for initial treatment of chronic hepatitis C in Korea (in Korean). Korean J Hepatol 2006;12:31-40.

-8 Lee SD, Yu ML, Cheng PN, et al: Comparison of a 6-month course peginterferon alpha- $2 \mathrm{~b}$ plus ribavirin and interferon alpha-2b plus ribavirin in treating Chinese patients with chronic hepatitis C in Taiwan. J Viral Hepat 2005; 12:283-291.
} 
9 Liu CH, Liu CJ, Lin CL, et al: Pegylated interferon-alpha-2a plus ribavirin for treatmentnaive Asian patients with hepatitis $C$ virus genotype 1 infection: a multicenter, randomized controlled trial. Clin Infect Dis 2008; 47 : 1260-1269.

10 Rao H, Wei L, Yang R, et al: IL28B genotype and IFNL4 ss469415590 $\Delta \mathrm{G}$ variant are both associated with response to pegylated IFN- $\alpha$ and ribavirin therapy in Chinese patients with chronic hepatitis C (poster 1899). Hepatology 2013;58:1123A.

-11 Tangkijvanich P, Komolmit P, Mahachai V, et al: Response-guided therapy for patients with hepatitis $C$ virus genotype 6 infection: a pilot study. J Viral Hepat 2012;19:423-430.

$\checkmark 12$ Tsang OT, Zee JS, Chan JM, et al: Chronic hepatitis $\mathrm{C}$ genotype 6 responds better to pegylated interferon and ribavirin combination therapy than genotype 1. J Gastroenterol Hepatol 2010;25:766-771.

13 Mauss S, Berger F, Vogel M, et al: Treatment results of chronic hepatitis $C$ genotype 5 and 6 infections in Germany. Z Gastroenterol 2012;50:441-444.

-14 Nguyen MH, Trinh HN, Garcia RT, et al: Higher rate of sustained virologic response in chronic hepatitis $C$ genotype 6 treated with 48 weeks versus 24 weeks of peginterferon plus ribavirin. Am J Gastroenterol 2008;103:11311135.

15 Nguyen NH, Vutien P, Trinh HN, et al: Treatment response and tolerability to pegylated interferon (PEG INF) and ribavirin (RBV) in treatment-naïve Asian American patients with chronic hepatitis $C$ and genotype $1,2 / 3$ and 6. Gastroenterology 2009;136:A791.

16 Pham TT, Ho DT: Pegylated interferon alfa2a plus ribavirin in chronic hepatitis $\mathrm{C}$ patients with genotype 6. Gastroenterology 2009; 136:A840.

17 Cai Q-X, Zhao Z, Zhang XH, et al: The high IL-28B CC genotype contribute to the good response of chronic hepatitis $\mathrm{C}$ genotype 6 in China. Hepatology 2011;54:829A.

-18 Seto WK, Tsang OT, Liu K, et al: Role of IL28B and inosine triphosphatase polymorphisms in the treatment of chronic hepatitis $C$ virus genotype 6 infection. J Viral Hepat 2013;20: 470-477.

19 Shao X, Zhao Z, Cai Q, et al: The dynamic analysis of the Th1/Th2 ratio during the interferon alpha/ribavirin combination therapy for HCV genotype 6 infected patients J Hepatol 2012;56:S66-S67.

-20 Thu Thuy PT, Bunchorntavakul C, Tan Dat H, Rajender Reddy K: A randomized trial of 48 versus 24 weeks of combination pegylated interferon and ribavirin therapy in genotype 6 chronic hepatitis C. J Hepatol 2012;56: 1012-1018.

21 Lam KD, Trinh HN, Do ST, et al: Randomized controlled trial of pegylated interferon-alfa $2 \mathrm{a}$ and ribavirin in treatment-naive chronic hepatitis C genotype 6. Hepatology 2010;52: 1573-1580.
22 Ollendorf DA, Tice JA, Pearson SD: The comparative clinical effectiveness and value of simeprevir and sofosbuvir for chronic hepatitis $\mathrm{C}$ virus infection. JAMA Intern Med 2014; 174:1170-1171.

23 Sovaldi ${ }^{\circledR}$ (sofosbuvir) [package insert]. Foster City, Gilead Sciences, 2013.

24 Médecins sans Frontières: Global response to hepatitis $\mathrm{C}$ hangs on access to new oral drugs. Médecins sans Frontières, 2014. http://www. msf.org.za/msf-publications/global-response-to-hepatitis-c-hangs-on-access-tonew-oral-drugs (accessed May 4, 2014).

25 Lawitz E, Mangia A, Wyles D, RodriguezTorres M, et al: Sofosbuvir for previously untreated chronic hepatitis $\mathrm{C}$ infection. N Engl J Med 2013;368:1878-1887.

26 Higgins JPT, Green S (eds): Cochrane Handbook for Systematic Reviews of Interventions Version 5.1.0 (updated March 2011). The Cochrane Collaboration, 2011. www.cochranehandbook.org.

27 Nguyen NH, VuTien P, Garcia RT, et al: Response to pegylated interferon and ribavirin in Asian American patients with chronic hepatitis $C$ genotypes 1 vs $2 / 3$ vs 6 . J Viral Hepat 2010;17:691-697.

28 Yuen MF, Lai CL: Response to combined interferon and ribavirin is better in patients infected with hepatitis $C$ virus genotype 6 than genotype 1 in Hong Kong. Intervirology 2006; 49:96-98.

29 Pham TT, Ho DT: An optimal duration of treatment for chronic hepatitis $\mathrm{C}$ genotype 6 patients. Hepatology 2011;54:810A.

30 Lam KD, Trinh HN, Do ST, et al: Randomized controlled trial of pegylated interferon-alpha $2 \mathrm{a}$ and ribavirin in patients with treatmentnaive chronic hepatitis $\mathrm{C}$ genotype 6 . Gastroenterology 2010;138:S783

31 Thi TTP, Ho TD: Pegylated interferon alfa-2a plus ribavirin in chronic hepatitis $\mathrm{C}$ patient with genotype 6. Hepatol Internat 2009;3:49.

32 Seong MH, Kil H, Kim JY, et al: Clinical and epidemiological characteristics of Korean patients with hepatitis $C$ virus genotype 6 . Clin Mol Hepatol 2013;19:45-50.

33 Thanak P, Kitiyakara T, Intaraprasong P, et al: Real-world outcomes of hepatitis $\mathrm{C}$ treatment in Thai patients. J Gastroenterol Hepatol 2012;27:247.

34 Weinstein T, Levine J: Early virologic response in children with hepatitis $\mathrm{C}$ genotype 6e. J Pediatr Gastroenterol Nutr 2009;49:1.

35 Lenz O, Vijgen L, Berke JM, et al: Virologic response and characterisation of HCV genotype 2-6 in patients receiving TMC435 monotherapy (study TMC435-C202). J Hepatol 2013;58:445-451.

36 Hui CK, Yuen MF, Sablon E, et al: Interferon and ribavirin therapy for chronic hepatitis $\mathrm{C}$ virus genotype 6: a comparison with genotype 1. J Infect Dis 2003;187:1071-1074.
37 Bunchorntavakul C, Siripun A, Chavalitdhamrong D: Fluvastatin monotherapy for the treatment of patients with chronic hepatitis C: a randomized double-blinded placebocontrolled study. Am J Gastroenterol 2011; 106:S102-S103.

38 Chu T, Kulkarni R, Gane EJ, Roberts SK, Stedman C, Angus P, Ritchie B, Lu XY, Ipe D, Lopatin U, Germer S, Iglesias V, Elston R, Berry MM, Smith PF, Shulman NS: The effect of host IL28B genotype on early viral kinetics during interferon-free treatment in patients with chronic hepatitis $\mathrm{C}(\mathrm{CHC})$. J Hepatol 2011;54:S521.

39 Cheng JT, Hsien C, Sun HE, Tong MJ: The emerging importance of chronic hepatitis $\mathrm{C}$ infection in Asian Americans. Am J Gastroenterol 2006;101:2737-2743.

40 Pham TTT, Ho DT: Impact of single nucleotide polymorphisms of IL28B on SVR in treatment chronic hepatitis $C$ genotype 6 in Vietnamese (poster 365). Hepatol Int 2013;7:S366.

41 Chen XY, Zhang Y, Rao H, et al: A prospective, randomized, open-label, multicenter study of response-guided therapy (RGT) for HCV treatment-naïve Chinese patients with chronic hepatitis C. Hepatol Int 2013;7:S724.

42 Han B, Mo H, Wong KA: In vitro analyses of HCV NS5B S282T mutants in multiple HCV genotypes show low levels of reduced susceptibility to sofosbuvir (GS-7977), no cross resistance to other classes of direct-acting antivirals, and hypersensitivity to ribavirin. Hepatology 2012;56:711A.

43 Lim JH: Changes in serum lipid profile before and after interferon therapy in patients with chronic hepatitis C. Hepatol Int 2012;6:170.

44 Loh PY: Outcome of hepatitis C treatment and effect of treatment dose adjustment in treatment naïve Asian populations. Hepatol Int 2013;7:S411.

45 Chao DT, Abe K, Nguyen MH: Systematic review: epidemiology of hepatitis $C$ genotype 6 and its management. Aliment Pharmacol Ther 2011;34:286-296.

46 Seto WK, Tanaka Y, Liu K, et al: The effects of IL-28B and ITPA polymorphisms on treatment of hepatitis C virus genotype 6. Am J Gastroenterol 2011;106:1007.

47 Antaki N, Marcellin P: What is the safe duration of therapy for patients infected with HCV genotype 6? Nat Clin Pract Gastroenterol Hepatol 2009;6:78-79.

48 Nguyen MH, Keeffe EB: Prevalence and treatment of hepatitis $C$ virus genotypes 4,5 , and 6. Clin Gastroenterol Hepatol 2005;3:S97S101.

49 Chow WC, Ng HS: Hepatitis C, E and G virus - three new viruses identified by molecular biology technique in the last decade. Ann Acad Med Singapore 1997;26:682-686.

50 Nguyen LH, Nguyen MH: Systematic review: Asian patients with chronic hepatitis $\mathrm{C}$ infection. Aliment Pharmacol Ther 2013;37:921936 
51 Al Naamani K, Al Sinani S, Deschênes M: Epidemiology and treatment of hepatitis $\mathrm{C}$ genotypes 5 and 6. Can J Gastroenterol 2013; 27:e8-e12.

52 Lai W: Viral hepatitis C - Asia-Pacific perspectives and guidelines. J Gastroenterol Hepatol 2012;27:27.

53 Chutaputti A: Managing HCV genotype 6 patients (abstract AA-05). Hepatol Int 2011;5: 47.

54 McHutchison JG: The role of genetic markers in hepatitis $C$ virus therapy: a major step for individualized care. Liver Int 2011;31(suppl 1):29-35.
55 Thomas DL, Thio CL, Martin MP, et al: Genetic variation in IL28B and spontaneous clearance of hepatitis C virus. Nature 2009;461:798-801.

56 Fried MW, Shiffman ML, Reddy KR, et al: Peginterferon alfa-2a plus ribavirin for chronic hepatitis $\mathrm{C}$ virus infection. N Engl J Med 2002;347:975-982.

57 Yu ML, Dai CY, Huang JF, Chiu CF, Yang YH, Hou NJ, Lee LP, Hsieh MY, Lin ZY, Chen SC, Hsieh MY, Wang LY, Chang WY, Chuang WL: Rapid virological response and treatment duration for chronic hepatitis $\mathrm{C}$ genotype 1 patients: a randomized trial. Hepatology 2008;47:1884-1893.
58 Backx M, Lewszuk A, White JR, et al: The cost of treatment failure: resource use and costs incurred by hepatitis $C$ virus genotype 1 -infected patients who do or do not achieve sustained virological response to therapy. J Viral Hepat 2014;21:208-215.

59 Cai Q-X, Zhao Z, Lin CS, et al: Shortened treatment duration in treatment-naive genotype 6 chronic hepatitis $C$ patients with rapid virological response: a randomized controlled trial. Hepatology 2013;58:1098A.

60 Nguyen NH, VuTien P, Garcia RT, et al: Response to pegylated interferon and ribavirin in Asian American patients with chronic hepatitis $C$ genotypes 1 vs $2 / 3$ vs 6 . J Viral Hepat 2010;17(10):691-697. 